\title{
Optical properties of d.c. magneto sputtered tantalum and titanium nanostructure thin film metal hydrides
}

\author{
M SINGH*, S SRIVASTAVA, S AGARWAL, S KUMAR and Y K VIJAY \\ Department of Physics, University of Rajasthan, Jaipur 302 004, India
}

MS received 19 April 2009; revised 20 May 2009

\begin{abstract}
Nanostructured thin films of tantalum and titanium were deposited on glass substrate using d.c. magnetron sputtering technique under the argon gas environment at a pressure of $0 \cdot 1 \mathrm{mbar}$. Optical transmission and absorption studies were carried out for these samples with pressure of hydrogen. Large changes in both transmission and absorption on loading these films with hydrogen are accompanied by significant phase changes and electronic transformation. Optical photograph shows the colour variation after hydrogenation in case of tantalum film which may be used as decorative mirrors and hydrogen sensors. The hydrogen storage capability of thin films was confirmed by variation in optical properties.
\end{abstract}

Keywords. Optical properties; sputtering; thin films; hydrogen pressure; transmission and absorption.

\section{Introduction}

Metal hydrides are projected for many applications including the development of technologies for storage, production and purification of hydrogen for clean energy production (Sandrock 1999). Before that several metal powders including titanium, zirconium, niobium and tantalum were commonly processed by the well known hydride-dehydride (HDH) technique (German 1984). There are many different allotropic forms for titanium hydrides (Numakura et al 1984; Woo et al 1985) such as $\alpha, \beta$ and $\delta$-phases given away in the $\mathrm{Ti}-\mathrm{H}$ phase diagram (Massalski et al 1986) depending on the hydrogen concentration, temperature and applied pressure.

According to the phase diagram of the Ta-H system, as reported by Ducastelle et al (1970) and later by Schober and Carl (1977), nine ordered phases of tantalum hydride of different stoichiometries were found to exist at low temperatures, but only the disordered $\alpha$-phase exists at temperatures higher than $350 \mathrm{~K}$. A review concerning the order-disorder transitions in group transition metal hydrides (V, Ni and Ta hydrides) was published by Harabayashi and Anano (1981). The structural investigations were carried out by neutron diffraction and thermal analysis (Ducastelle et al 1970; Schober and Carl 1977; Harabayashi et al 1981) for tantalum hydrides. The order-disorder transition in metal hydrides is linked to presence of interstitial hydrogen atoms. They were located in either tetrahedral or octahedral interstitial positions in metals.

\footnotetext{
*Author for correspondence (mangej_singh@yahoo.com)
}

Since the discovery of the switchable mirrors based on $\mathrm{YH}_{x}, \mathrm{LaH}_{x}$ and rare earth hydride $\left(\mathrm{REH}_{x}\right)$ films (Huiberts et al 1996), a lot of research has been done on metals and their compositions. The special characteristics of these mirrors is that they can be continuously and reversibly switched between a metallic reflecting state to an insulating transparent state by the absorption of hydrogen. Effect of hydrogen on optical properties used in different applications such as gasochromic (Huiberts et al 1996), electrochromic (Notten et al 1996; Armitage et al 1999) or chemochromic (Vander Sluis et al 1999), photochromic (Hoekstra et al 2001), piezochromic (Wijngaarden et al 2000) and thermochromic (Giebles et al 2002). These materials are also interesting for hydrogen storage applications (Schlapbach and Zuttel 2002; Farangis et al 2003). Hence, in conclusion, one can say that thin film of metal hydride can be used for many applications as smart windows, switchable mirrors, hydrogen sensors and hydrogen storage. In this paper we are going to present the effect of hydrogen absorption on optical properties of nanostructure thin films.

\section{Experimental}

Magnetron sputtering has become the process of choice for the deposition of wide range of important coatings, low fraction coatings, wear resistant coatings, corrosion resistant coating, decorative coatings and coating with specific optical and electrical properties (Kelly and Amell 2000). We deposited nanostructured thin films using d.c. magneto sputtering unit (Vacuum Equipment Co, New Delhi) in an argon gas environment at a pressure of 

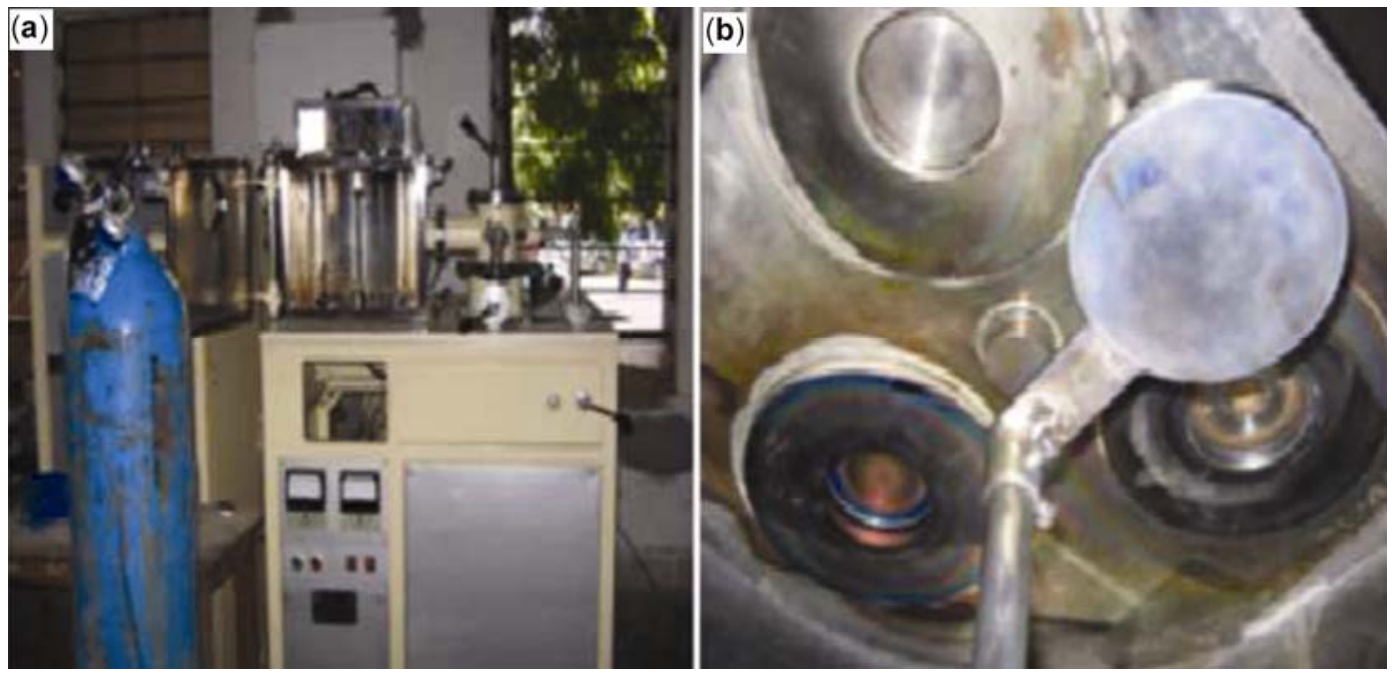

Figure 1. Sputtering unit with multiple targets. (a) View of sputtering unit with Argon cylinder and (b) direct sputtering with three target and substrate holders.

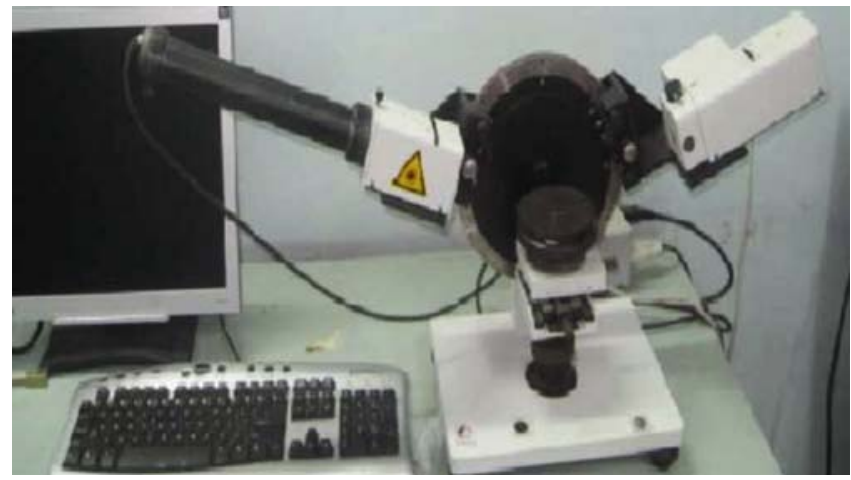

Figure 2. Ellipsometry with computer.

$0 \cdot 1$ mbar. The sputtering unit with sample holder and multiple targets are shown in figure 1. Magnetron sputtering is a powerful and flexible technique to deposit thin films of materials, any metal or alloy or compounds by sputtering of atomized material from a solid due to energetic bombardment on surface layers. We have arranged target at lower position and placed substrate holder above them for thin film deposition. A sheet of pure tantalum and titanium having two inch diameter and thickness, $2 \mathrm{~mm}$, was used as target material. Thin films were deposited on clean glass substrate using argon gas ions to sputtered tantalum and titanium with a deposition rate, $2.5 \mathrm{~nm} / \mathrm{s}$. Thickness was measured using ellipsometry as shown in figure 2 for tantalum and titanium thin films. It was found to be $216 \mathrm{~nm}$ and $233 \mathrm{~nm}$, respectively. The ellipsometry is a non-destructive optical technique, which deals with the measurement and interpretation state of polarized light undergoing oblique reflection from a sample surface. The ellipsometry is based on measuring the changes of the amplitude and phase of polarized light when reflected on a sample surface. The high sensitivity on phase changes during reflection makes ellipsometry as one of the most precise and accurate methods to measure the thickness of films. Our ellipsometry have polarizer for polarized incident light and analyser for received reflected light from thin film surface. It was well connected with computer program to measure thickness. These films were hydrogenated in gas loading hydrogen absorption chamber with increasing hydrogen pressure at room temperature. The optical transmission and absorption spectra of these films recorded using a Hitachi photo-spectrometer model 330 in the range from 800$300 \mathrm{~nm}$. An optical micrograph was also recorded before and after hydrogenation by using lamobed optical microscope. X-ray fluorescence (XRF) studies were carried out for titanium and tantalum thin films to test the purity of sputtered films. The X-rays were exited by using Am-241 source of $45 \mathrm{mCi}$ placed in a lead collimator, 90 degree scattering geometry was used for excitation of X-rays in different samples in the range of $1 \cdot 0-30 \mathrm{keV}$. A silicon drifted peltier cooled $5 \mathrm{~mm}$ detector was used having a resolution of $150 \mathrm{eV}$ at $6 \cdot 4 \mathrm{keV}$. The X-ray emitted from different elements was detected and spectra recorded in computer for analysis.

\section{Results and discussion}

\subsection{Transmission and optical microscope studies of tantalum thin film}

Figure 3 shows transmission vs energy spectra of tantalum thin film. In this spectra one can observe that after hydrogenation transmission was found to be reduced. The reduced transmission in these films correlated with absorption of hydrogen and residual content of metal with 
hydride phase. Similar effect was observed by Schlapbach and Zuttel (2002) for hydrogen storage applications. The optical transmission studies also suggest that there is no significant hydrogen absorption on pressure, 5 Psi, at room temperature, but at pressure, $10 \mathrm{Psi}$, the transmission was found to be reduced that shows optical properties had been changed with concentration of hydrogen, it also suggested change of phase from one to other state with hydrogenation. Yoshimura et al (2002) observed composition dependent transmittance in the hydride state which decreases abruptly for $x<0.1\left(\mathrm{MgNi}_{0 \cdot 1}\right)$ and $x>0.3$ $\left(\mathrm{Mg}_{3.3} \mathrm{Ni}\right)$ and that decrease was correlated with residual metal content in layers.

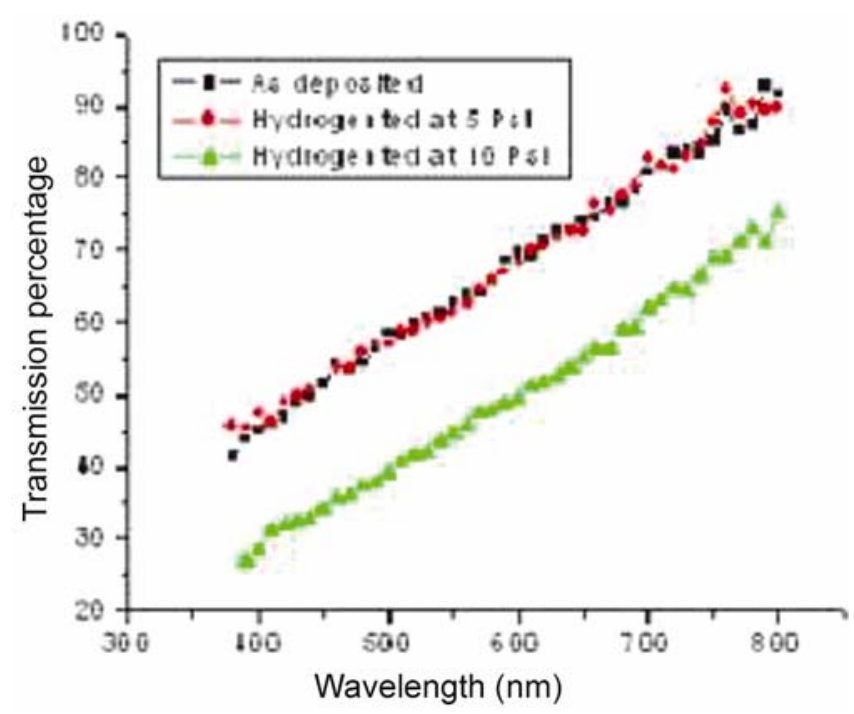

Figure 3. Transmission spectra of tantalum thin films.

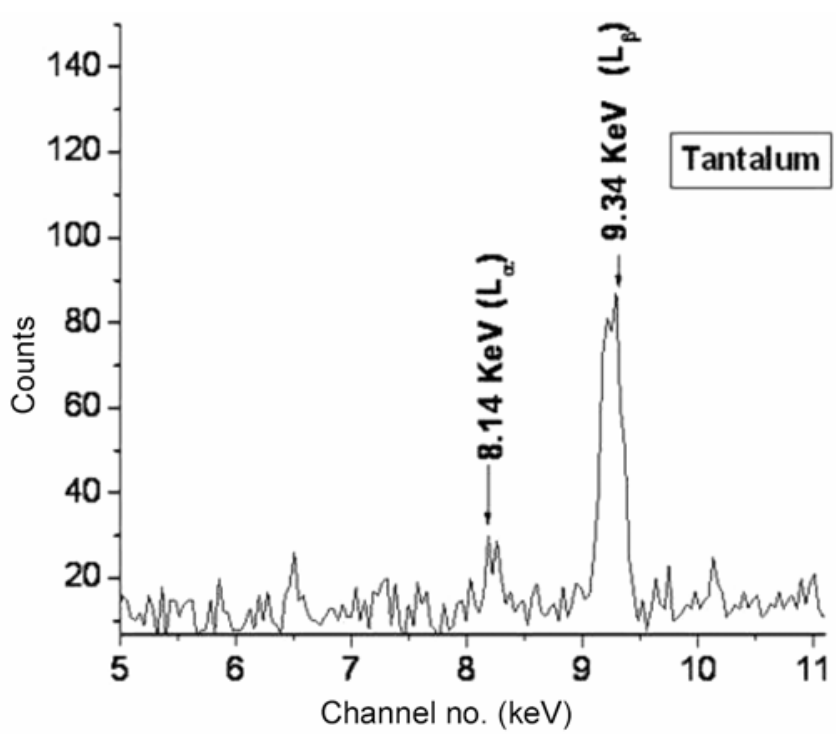

Figure 4. XRF of tantalum thin films.
The absorption of hydrogen did not occur up to 5 Psi pressure, it may be due to the fact that thin film requires high pressure for activation. The optimum or minimum pressure required was 10 Psi for tantalum thin films. Still optimum pressure required more careful studies because we have not taken measurement between 5 Psi and 10 Psi. The XRF of that film carried out to test the purity of films after deposition is shown in figure 4 . The $L_{\alpha}$ and $L_{\beta}$ peaks of tantalum appeared at $8.14 \mathrm{keV}$ and $9.34 \mathrm{keV}$, respectively. The $K_{\alpha}$ and $K_{\beta}$ peaks were not observed due to limitation of detector.

The optical photograph has been taken at a magnification of $40 \mathrm{X}$ by using Labomed optical microscope. Figures 5 and 6 show optical photographs for as deposited and hydrogenated tantalum thin films, respectively. One can see a lot of open space on surface, it may be due to order of thickness which was a few nanometer. At the nanometer scale during the growth process, channel formation and percolation take place. Percolation means that grains are connected electrically within metal layer on insulating glass substrate. The irregular morphology was also

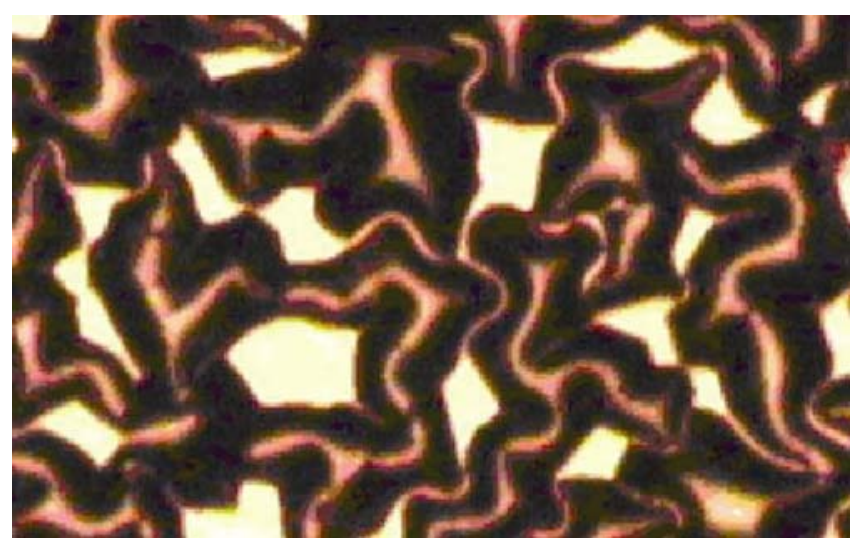

Figure 5. Optical photograph of as deposited thin films in reflectance mode.

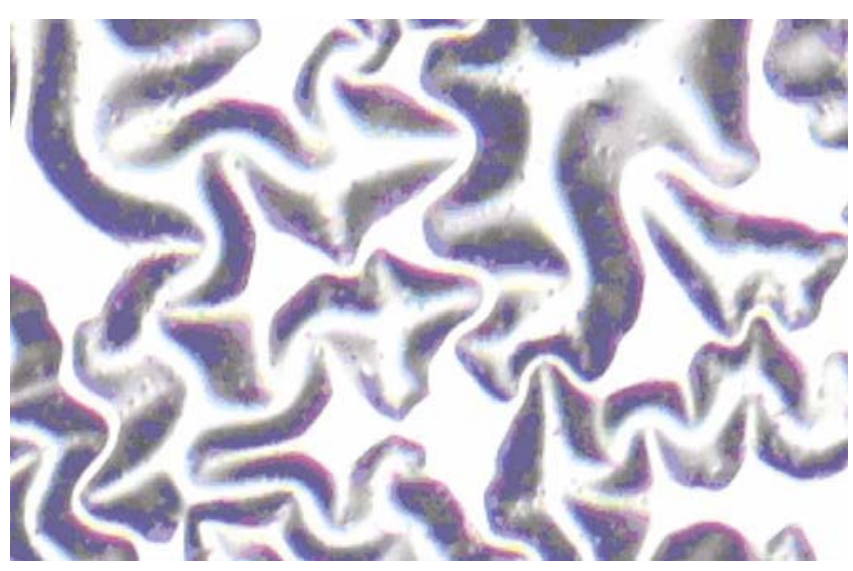

Figure 6. Optical photograph of hydrogenated thin films in reflectance mode. 
observed (Kaiser 2002) and is explained on the basis of percolation in thin films.

We have also observed variation of colour from red to gray after hydrogenation. The colour variation correlated with phase change with hydrogenation as well as indication of hydrogen storage in films. It was suggested that tantalum thin film may be used as decorative mirrors for visible light with variation of hydrogen pressure. The variation in colour with hydrogenation in case of $\mathrm{YH}_{x}$ was observed by Huiberts et al (1996) that agreed with our present results in tantalum thin films. The colour variation in case of $\mathrm{Co}-\mathrm{Mg}$ and $\mathrm{Ni}-\mathrm{Mg}$ was observed by Farangis et al (2003).

\subsection{Optical and XRF studies of titanium thin films}

Figure 7 shows the absorption vs wavelength spectra of nanostructure titanium thin film. In the spectra, we saw

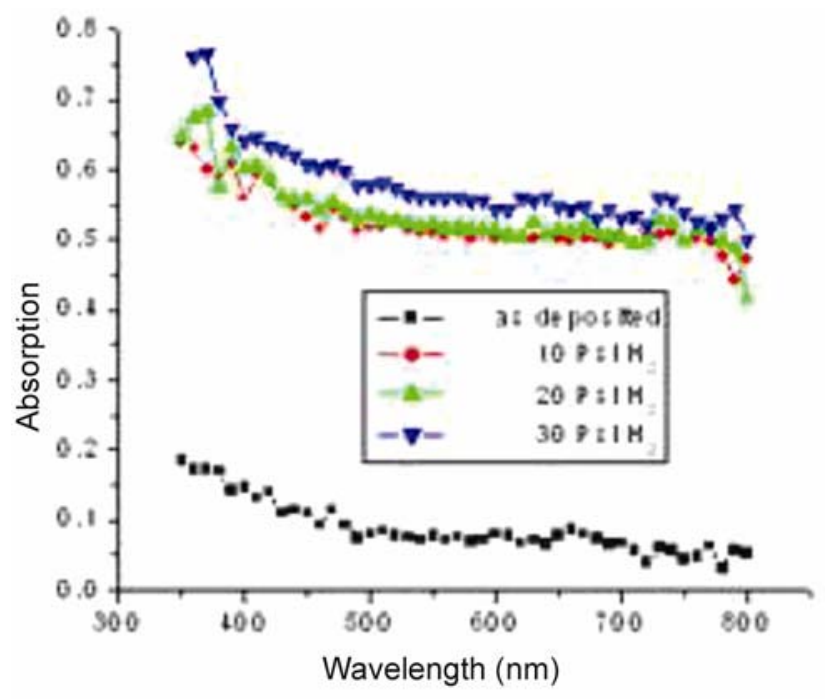

Figure 7. Absorption spectra of titanium thin films.

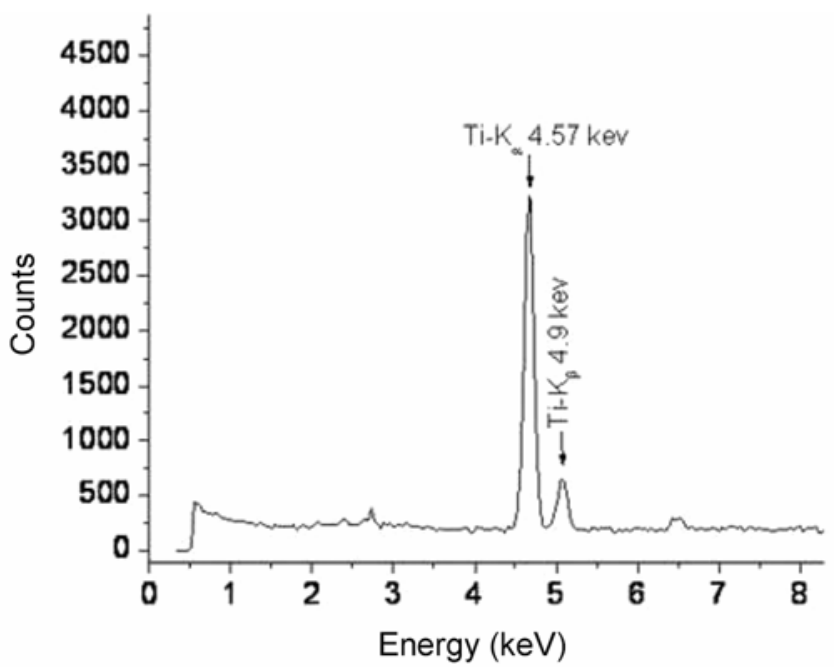

Figure 8. XRF of titanium thin films. that absorption increased with increasing hydrogen pressure. Hence one can say that absorption of hydrogen in film decreases the transmission of light. It means that the titanium thin film has the same behaviour as tantalum thin film in transmission mode. Hence we can conclude that titanium and tantalum thin films at nanostructured level do not show switchable behaviour as observed in rare earth and transition metal reported in literature. The optical photograph was taken for this film. It does not show any colour variation with hydrogenation so it cannot be used for decorative mirrors but it can be used as hydrogen sensors. It was also suggested that titanium films absorbed more hydrogen with pressure than tantalum thin films.

Figure 8 shows X-ray fluorescence (XRF) spectrum of magnetron sputtered nanostructured titanium thin films that contain only pure titanium peaks $K_{\alpha}$ and $K_{\beta}$ at $4.5 \mathrm{keV}$ and $4.9 \mathrm{keV}$, respectively without any impurity. After deposition, thin film samples bring in atmospheric pressure at room temperature.

\section{Conclusions}

Thin film of tantalum may be used as hydrogen storage, decorative mirrors and sensors. Thin film of titanium was used only for storage and sensors and not for decorative mirrors and variation of optical properties could be used as an indicator tool for hydrogen storage. The titanium and tantalum thin films at nanostructured level do not show switchable behaviour as observed in rare earth and transition metal reported in literature.

\section{Acknowledgements}

The authors are thankful to DSA program for providing the sputtering unit and UGC, New Delhi, for financial support. One of the authors (MS) is grateful to ICTP, Italy, for awarding a regular associateship and providing library and computer office facilities for this work.

\section{References}

Armitage R, Rubin M, Richardson J, Brien N O and Chem Y 1999 Appl. Phys. Lett. 751863

Ducastelle F, Caudrom R and Costa P 1970 J. Phys. Chem. Solids 311247

Farangis B, Nachimuthu P, Richardson J J, Slack J L, Meyer R C, Perera C and Rubin M D 2003 Solid State Ionics 165 309

German RM 1984 Powder metallurgy science (Princeton: MPFI)

Giebles I A M E, Vander Molen S J, Griessen R and Divece M 2002 Phys. Lett. 801343

Harabayashi M and Anano H 1981 Order-disorder phenomena in metal hydrides (ed.) G Bambakidis (New York: Plenum Press) p. 55 
Hoekstra AF Th, Roy A S, Rosenbaum TF, Griessen R, Wijngaarden R J and Koeman N J 2001 Phys. Rev. Lett. 86 5349

Huiberts J N, Griessen R, Rector J H, Wijngaarden R J, Dekker J P, De Groot D G and Koeman N J 1996 Nature (London) 380231

Kaiser N 2002 Appl. Opt. 413053

Kelly P J and Amell R D 2000 Vacuum 56159

Massalski T B, Subramanian P R and Okamoto H (eds) 1986 Binary alloy phase diagrams (Metals Park, Ohio: ASM International)

Notten P H L, Kremers M and Griessen R 1996 J. Electrochem. Soc. 1433348
Numakura H and Koiwa M 1984 Acta Metall. 321799

Schlapbach L and Zuttel A 2002 Nature (London) 414 313

Schober T and Carl A 1977 Scr. Metall. 11397

Sandrock G A 1999 J. Alloy Compd. 293-295 877

Vander Sluis P 1999 Electrochem. Acta 443063

Wijngaarden R J, Huiberts J N, Nagengast D, Rector J N, Griessen R, Hantland M and Zontone F 2000 J. Alloys Compd. $\mathbf{3 0 8} 49$

Woo O T, Weatherley G C, Coleman C E and Gilbert R W 1985 Acta Metall. 331897

Yoshimura K, Yamada Y and Okada M 2002 Appl. Phys. Lett. 814709 